\title{
DERECHO Y LITERATURA: EL PROYECTO DE MARTHA NUSSBAUM *
}

\author{
M. Jimena Sáenz \\ CONICET-UNLP \\ mjimenasaenz@hotmail.com
}

RESUMEN. Este trabajo presenta una lectura de lo que Nussbaum llamó su «proyecto filosófico-literario" que permite vislumbrar cuál es su aporte y mirada distintiva a la discusión sobre las relaciones entre el derecho y la literatura. En base a esta lectura, se plantean una serie de "usos" que de esta pueden hacerse en el campo jurídico, o una serie de puntos donde el diálogo puede ser productivo.

Palabras clave: derecho y literatura, filosofía angloamericana y literatura, NusSBAUM.

\section{Law and Literature: the Project of Martha Nussbaum}

ABSTRACT. This paper offers a reading of what NUSSBAUM called her «literary-philosophical project» that aims to show the contribution and the distinctive perspective that the author brings to the field of «law and literature». Based on this reading, it proposes three «uses» of literature in the world of the law, or three points in which the dialogue between law and literature can be productive.

Keywords: law and literature, angloamerican philosophy and literature, NuSSBAUM.

* Fecha de recepción: 13 de agosto de 2018. Fecha de aceptación: 12 de febrero de 2019. 


\section{INTRODUCCIÓN}

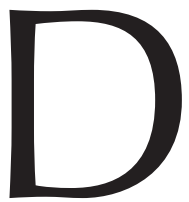

urante la década de 1970 en el ámbito de la academia norteamericana, cobró fuerza institucional lo que se conoce como el movimiento «derecho y literatura». A partir de allí, el movimiento creció hasta incluir líneas y agendas de trabajo tan difíciles de catalogar como de reunir bajo un rótulo único; se expandió a través de las fronteras; y tuvo su momento de auge y entrada al mainstream de la discusión jurídica durante los años ochenta cuando propulsó de distintos modos la consideración del problema de la interpretación. Si bien este último es el aspecto más difundido y conocido del «derecho y la literatura», este trabajo propone revisar un proyecto que surgió durante ese mismo momento pero pareció quedar opacado por desarrollos subsiguientes o concomitantes: el proyecto filosófico-literario de Martha NussBaum.

La obra de NuSSBAUM es vasta y lo prolífico es una de las características que la definen. Esta también se ha caracterizado por los cambios o giros en sus preocupaciones o ámbitos de preocupación. Así lo señala ella misma en un simposio que tenía por objeto discutir su obra, quejándose de que los trabajos tomaban «ideas de diversos estratos cronológicos» como si fueran compartimentos estancos, sin registrar en la diacronía los matices y giros que se produjeron (Nussbaum, 2000: 102). Entre esos giros, la literatura aparece desde los comienzos de su producción y permea toda su obra — sea como objeto específico de análisis, como referencia, como fuente de pensamientoAquí me interesa entonces desplegar una visión de conjunto que de inteligibilidad a la gran cantidad de trabajos producidos entre 1980 y la primera década del tercer milenio, y delimitar dos grandes momentos en la obra de NUSSBAUM que circunscriben dos formas de relación entre la literatura, la filosofía y el derecho que se entrelazan. El primer momento agrupa sus trabajos de la década de los ochenta centrados en la filosofía moral; el segundo, sus trabajos de la década de los noventa —y posterioresque amplían abiertamente el rango de sus preocupaciones hacia la filosofía política y el derecho ${ }^{1}$. Con este panorama pretendo recuperar también la primera parte de su obra que transcurre durante los ochenta, como parte de la reflexión sobre la literatura de NussBaum útil para pensar algunas dimensiones o núcleos propios del derecho que usualmente queda o bien opacada por sus textos de la década de los noventa, o directamente excluida de los análisis que focalizan en el «giro literario del pensamiento político» (STOW, 2007) o el «giro literario en la academia legal» como lo llamó POSNER (Posner, 1998: 305; Botero Bernal, 2014).

1 Estas dos fases son claramente delimitadas por Geoffrey HARPHAM (2006) que suele ser la referencia de todos los trabajos que periodizan la obra de NUSSBAUM. HÄMÄLÄINEN encuentra también una «división en dos» en la obra de NUSSBAUM marcada por un cambio desde una «preocupación por cuestiones de moral personal y desarrollo moral» hacia «cuestiones de justicia social, distribución de la riqueza, deberes de la sociedad hacia el individuo y cuestiones de derechos humanos»; un desplazamiento de sus figuras guía en la década de los ochenta -MURDOCH y B. WILLIAMS - hacia RAWLS y KANT en los noventa; un correlativo cambio en los blancos que tenía en mente en cada momento: el kantismo y el utilitarismo en tanto enfoques que enfatizaban o bien la conmensurabilidad de los valores o se centraban exclusiva y excluyentemente en los principios y las reglas en desmedro de la «percepción»; hacia una focalización en la crítica al utilitarismo en los noventa; así como un viraje en el vocabulario filosófico que pasa de la virtud y la percepción a los derechos, los principios abstractos y la justicia social (2016: 137). 
En lo que sigue, el trabajo se organiza del siguiente modo. La sección 1 intenta aclarar la posición de NUSSBAUM en relación al movimiento «derecho y literatura» para precisar cuál es el aporte y la mirada distintiva que allí presenta. La sección 2 se dedica a examinar la primera etapa de su obra en donde la literatura y la reflexión sobre por qué es relevante para la filosofía angloamericana, cómo deberían pensarse las relaciones entre ambas y para qué introducirla en la conversación filosófica es una de sus preocupaciones centrales. Allí se definen al menos dos cuestiones que tendrán proyecciones en su pensamiento sobre el derecho: un modo de relación que privilegia mantener la diferencia entre los dos objetos y disciplinas, y un eje desde el que se plantea la relación, la experiencia de lectura ordinaria. La sección 3 se dedica a leer la segunda etapa de la obra de NuSSBAUM en la que el derecho cobra prominencia, en función de la diferencia que la autora había identificado como el gran aporte de la literatura. Esa diferencia estaba centrada en el rol de la contingencia y la vulnerabilidad; y el lugar de la percepción y las emociones en el razonamiento moral y luego jurídico.

\section{NUSSBAUM Y EL MOVIMIENTO «DERECHO Y LITERATURA»}

Si bien Martha NusSBAUM aparece en la bibliografía y en el imaginario que rodea al «movimiento derecho y literatura» como una autora central, una figura multicitada y alistada en las filas de quienes quieren recuperar alguna variante de lo «literario» para el pensamiento jurídico, su posición en relación al movimiento es, por varias razones, extraña y en un punto dislocada.

NuSSBAUM es una figura extraña en primer lugar, por las razones más obvias y que afloran en la superficie: está formalmente y en sentido estricto, fuera de los terrenos que el «derecho y la literatura» intenta vincular, fuera del campo legal y fuera también del campo literario. En Justicia Poética (JP) había señalado su extranjería en relación al derecho: «Sigo siendo una aficionada en cuestiones legales, y [...] hago esta sugerencia desde afuera, con gran ignorancia del aspecto más técnico y formal del derecho —al que no deseo restar jerarquía y por el cual siento un gran respeto- $\longrightarrow(1997: 17)^{2}$.

Su carácter externo a los estudios literarios asume matices aún más extremos. Si bien desde los comienzos de su carrera filosófica, la obra de Nussbaum se mantuvo fuertemente ligada a la literatura, y esa es quizá la característica central de su firma filosófica, su figura no solo es ajena formalmente al ámbito literario en función de su formación disciplinar, sino que desde los inicios su proyecto filosófico-literario se construyó desde lo que los estudios literarios dejaban fuera. Así, en un ensayo de 1987 reunido luego en El conocimiento del amor [CA (1990), 2005], señalaba una «ausencia de lo ético» en la teoría literaria, no solo por la «ausencia de la filosofía moral» que contrastaba con la presencia de la epistemología y el análisis de distintos filósofos en general continentales (NIETZSCHE, HEIDEGGER, GADAMER, i. e.), sino también por la ausencia de «la pregunta metodológica de la filosofía moral y del sentido de apremio de la filosofía moral con estas cuestiones. La idea de que somos seres socia-

2 Aunque también es justo decir que NussBaum intentó llenar este hueco en repetidas ocasiones que se incrementan luego del 2000. Para una revisión completa del impacto del trabajo de Martha NussBaum en el derecho, vid. WEST (2015). 
les que tratamos de entender, en los momentos de gran dificultad moral, cuál podría ser, para nosotros, la mejor forma de vivir [...] no se encuentra en los escritos de los principales teóricos de la literatura» (2005:313-314). O bien, en la cúspide de lo que S. VLASCOS reseña como «una década dominada por las abstracciones multiformes del discurso literario teórico de la Alta Teoría» (2014: 3), explicita que «después de leer a Derrida [...] siento una cierta ansia de sangre; esto es, de escribir sobre literatura que habla de las vidas y elecciones humanas como si estas fueran importantes para nosotros» (2005: 314). En este sentido, y de la mano con su interés ético en la literatura, NussBAum parece otorgarle también una centralidad casi absoluta no al «lector profesional», «profesor de literatura» que lee «con desapego» (1998), «buscando teorías de la interpretación» (1997: 119), «a la manera desapegada del escéptico teórico de la interpretación» (1999: 371), sino al «lector común» o «lector ordinario» (2005: 66-70).

Aún en su ámbito natural, la filosofía, NussBaum también aparece como una figura difícil de ubicar. Desde el momento en que «asomó su cabeza al mundo filosófico» cuando fue invitada a la reunión de la American Philosophical Association (APA) entre 1980 y 1981, y decidió escribir lo que sería su primer trabajo sobre la relación literatura/filosofía para «salir del casillero estrecho de ser una especialista histórica» (Nussbaum, 2009: 758), el trasvasamiento de los casilleros puede considerarse también una marca de su trayectoria filosófica. Geoffrey HARPHAM (2006) caracteriza su carrera como «deconstructiva», a pesar de las resistencias que NuSSBAUM opondría a esta caracterización. El movimiento general que parece dirigir su obra es tomar elementos degradados o menores, que quedaban en los márgenes de la tradición filosófica principal, y llevarlos al centro de la escena. Así ocurre con el pensamiento filosófico griego que en los primeros años de la década de 1980, cuando ella lo reivindica, había quedado relegado a la «infancia» de la filosofía moderna; con la tragedia clásica, a la que le quita el barniz de objeto antiguo distanciado y experiencia extraña que borra las fronteras entre la agencia y la estructura, libertad y destino, para situarla en el terreno mundano: «no creo que dichos problemas sean solo el alimento de la tragedia; pienso que forman parte de los hechos cotidianos de la razón» (2015:33). Esto ocurre también con la novela, que quedaba fuera o en los márgenes de los intereses y materiales a los que recurría la investigación filosófica estándar de la posguerra; con las emociones, que eran excluidas de modelos altamente idealizados de la racionalidad o, en un plano más general, con psicología moral que pedía prestar más atención a la experiencia vívida del valor que al acabado perfecto de la teoría; y luego con su elección del punto de vista de la discapacidad y la animalidad para darle forma a su enfoque de las capacidades como teoría de la justicia parcial en contraposición a las teorías de base contractualista. Ese movimiento en su obra, que encaja de alguna forma en la clásica maniobra deconstructiva que señalaba HARPHAM, también puede ligarse de manera general a la mirada aristotélica que en este punto, como ella lo señala, coincide con la mirada que los estudios literarios le han adjudicado a la novela, y sobre todo a la novela realista que será el foco de interés en las etapas avanzadas de su obra. La primera es una mirada que ella definió en su primer libro, como «un gusto por lo ordinario y lo prosaico» que quedaba fuera de «las elevadas y rarificadas preocupaciones a que les tenía acostumbrados la filosofía» (2015: 338). En relación a la novela, señalaba: «Un rasgo que la separa [a la novela], hasta cierto punto de las [...] biografías e incluso los dramas trágicos: nominalmente, su interés en lo corriente, en las vidas cotidianas y en las luchas de la gente 
común [...] los lugares que visitamos en la novela [...] ninguno de estos lugares había sido escogido para albergar las tragedias de Sófocles o de Racine [...]. Al leer estas historias nos abrazamos a lo común, que se ha convertido para nosotros en un objeto de interés y compasión» (NussBaum, 1991: 21). En JP reiteraría este énfasis de la novela en lo común que se vuelve objeto de interés: «[h]ay otra característica de la lectura de novelas que es preciso destacar desde un principio: el interés de la novela por lo cotidiano [...] [e]sta era una característica del género desde su nacimiento, sobre todo en Inglaterra, y por eso está asociado con el surgimiento de la democracia» (1997: 34).

Desde esa posición extraña o dislocada, NussBAum ingresa de manera lateral al movimiento «derecho y literatura» durante los inicios de la década de los ochenta, en la cúspide del momento «hermenéutico» de importación de Alta Teoría literaria al ámbito del derecho como caja de herramientas útiles para enfrentar la interpretación de textos legales. Si bien puede fecharse el ingreso de NusSBAUM al movimiento durante los noventa, en el momento en que dicta las conferencias Alexander ROSENTHAL en la Facultad de Derecho de Northwestern $(1991)^{3}$, el primer eslabón de lo que ella llamó su «proyecto filosófico-literario» se sitúa en los primeros años de los ochenta, en el marco de otro contexto distinguible aunque relacionado, uno que, de manera más amplia, tenía como objeto la relación entre filosofía y literatura en el ámbito de la filosofía angloamericana. Con un pie entonces en la discusión sobre filosofía y literatura, la intervención de NuSSBAUM en el movimiento «derecho y literatura» tiene matices particulares.

Hacia los ochenta, el movimiento había desarrollado dos esquemas de relación entre el derecho y la literatura ${ }^{4}$. Los «humanistas» marcaban una diferencia inicial de la literatura, localizaban esa diferencia en los contenidos de la literatura e intentaban llevar esos contenidos al derecho, sea que se los designe como representaciones de actores, temas o espacios jurídicos que podían aportar una verdad sobre ellos; o como «contenidos éticos» de la literatura que se abstraen como proposiciones de las obras literarias. En los primeros años de los ochenta, el paradigma dominante del «derecho y la literatura», sin embargo, había girado por completo. No solo había abandonado el interés por las obras literarias, sino que también había logrado acercarse al canon central del pensamiento jurídico a partir de la creciente atención sobre la interpretación que tenía lugar en ese entonces. El momento «hermenéutico», entonces, acudía al campo literario en busca de modelos teóricos de amplio alcance que ayudaran a entender la empresa interpretativa del derecho. Su foco eran los textos legales, el material central que había que interpretar, y su principal objetivo era la actividad que llevaban adelante los jueces de las altas cortes. Así, tanto desde la mirada constructiva sobre el derecho como desde el ala crítica, se pensó a la interpretación jurídica como una especie del género interpretación que podía ser iluminada por las reflexiones sobre cómo llevar a cabo esa tarea en otros ámbitos. El tema aquí eran entonces las técnicas de lectura o in-

\footnotetext{
${ }^{3}$ Las conferencias conforman la base de lo que se publicaría luego como Justicia Poética [(1995) 1997].

4 Sigo en este punto la periodización de la producción del movimiento propuesta por BARON (1999) y PETERS (2005) que distinguen tres etapas: una «humanista» durante la década de los setenta; una «hermenéutica» en los ochenta; y una «narrativa» durante los noventa. He completado esta periodización incluyendo una etapa de «estudios culturales del derecho» que surge a fines de los noventa y adquiere más presencia en el 2000; y otra situada en los estudios literarios que se consolida en los primeros años del cambio de milenio como «derechos humanos y literatura» (SÁENZ, 2014).
} 
terpretación que habían producido los estudios literarios y que faltaban en el derecho, no el contenido o la verdad que la literatura podía aportar al campo jurídico.

NUSSBAUM aparece en ese marco casi a contracorriente, junto con un grupo de filósofos angloamericanos interesados en incluir a la literatura como parte de la reflexión filosófica. Lo que destaca a los filósofos en un contexto en el que la importación de Alta Teoría era la moneda corriente del cruce disciplinar literario, es su voluntad de introducir a las obras literarias mismas — en general, la novela — como parte de la reflexión filosófica. Y que lo hacían guiados justamente, como lo destaca HäMÄLÄINEN (2016), por un interés por contrarrestar cierta tendencia en la filosofía moral de posguerra a reducir la investigación filosófica a las formas de la teoría, a lograr el cerrado y acabado teórico perfecto que recorte una serie de procedimientos para encontrar los principios correctos para la acción moral; así como a reducir el vocabulario al argumento por sobre otras formas de expresión. Lo que en el derecho funcionaba como un deseo de generar una cultura teorética en una disciplina fuertemente asociada a una profesión y un marco abstracto capaz de generar reglas y principios para gobernar una actividad que se descubría confusa - la interpretación-; en la filosofía moral de posguerra funcionaba exactamente del modo inverso: el impulso hacia la literatura era, en general, una forma de ensanchar hacia abajo el ámbito de la moralidad que retrataba la abstracción teórica, «un intento de hacer a la filosofía más vívida frente a las preguntas morales de la vida real» (HÄMÄLÄINEN, 2016: 50); un «giro hacia la vida», hacia la «psicología moral»o «hacia la experiencia real del valor de los seres humanos en este mundo» (VOGLER, 2007: 6); un reclamo «contra la prolijidad» de la filosofía como lo caracteriza Jane ADAMSON (1998: 84)5.

Algo semejante señalan HORTON y BAUMEISTER en relación a la filosofía política (1996). Allí ellos reconstruyen el clima que llevó a los pensadores políticos hacia la literatura como uno de insatisfacción con la excesiva abstracción de la teoría y la centralidad del procedimiento deductivo; el carácter «descontextualizado y ahistórico» de los argumentos que producía; y sobre todo, su separación de la práctica y la vida política producida en parte, por el objetivo teorético principal de cerrado perfecto y simplificación. En ese contexto, expresan que «si la filosofía debe involucrarse más efectivamente con la práctica política debe volverse menos autorreferente; menos preocupada por ejemplo, con los problemas ingeniosos pero improbables de la teoría a gran escala, y más concentrada en mirar hacia el exterior y confrontar las realidades de la vida política. Adicionalmente, debería con certeza volverse menos ambiciosa en su escala, propósitos, y ocuparse menos de desarrollar una teoría general de la moralidad política y más de las contingencias y complejidades que son constitutivas de la política práctica» (1996: 12). Parte central de esa reorientación hacia las complejidades de la práctica y la vida política es para los autores el recurso a la literatura: «para desarrollar un entendimiento más rico, matizado y realista de la deliberación política, la literatura imaginativa puede tener un rol vital» (1996: 13).

5 En un sentido aún más extremo de este giro hacia la literatura como un giro hacia la experiencia real del valor de los seres humanos, varias de las firmas filosóficas asociadas a la inclusión de literatura son también alistadas en posiciones que directamente descartan o se oponen a la teorización sistemática o bien a los reclamos de la razón. Entre los primeros suelen citarse a B. Williams, R. RORTY y C. DiamOND; entre los segundos, a MACINTYRE. 
Por otro lado, NussBAum no parece interesada en la lectura literaria como interpretación, como forma o procedimiento distante para aislar significados, fijar sentidos de un texto y testearlos, que es el presupuesto de semejanza con el derecho que habilita la transferencia de modos y marcos interpretativos de la teoría literaria; ni tampoco en los modos de lectura del crítico literario — «el punto de vista disciplinar»- que desde el derecho se querían importar o de maneras más matizadas, traducir. Su propuesta se centra en cambio en la literatura como «experiencia del lector» (1997:38), en la experiencia de lectura que proporcionan y a la que invitan los textos literarios, y en las potencialidades y usos que esa experiencia pueda tener en el pensamiento filosófico, político y moral. Esos dos puntos diferenciales del planteamiento de NussBAuM, quizá alentados por su posición anómala o dislocada dentro del movimiento, son los que la presentan como una autora interesante para pensar los caminos que puede seguir la articulación del derecho y la literatura. NusSBAum presenta, por un lado, a la novela como un correctivo o complemento de la teoría como forma dominante en el ámbito filosófico sin destituir a esta última del pensamiento moral y político. Por otro lado, presenta un eje diferencial en el que situar la relación entre el derecho y la literatura, que no está vinculado a la teoría de la interpretación ni tampoco a las lecturas más centradas en el contenido del momento humanista del movimiento, sino a la experiencia de lectura ordinaria, una experiencia compleja o de «niveles múltiples» como la entiende PHELAN (2007), que reúne intereses cognitivos, elementos y disposiciones afectivas e intelectuales. En este sentido puede entenderse que NussBaum señale en JP que «no es preciso entonces considerar que una novela es políticamente correcta en todo sentido para apreciar la experiencia de baberla leído como políticamente valiosa» (1997: 112, cursiva añadida); y también que señale repetidas veces que su proyecto se basa en una descripción o una elaboración de la experiencia de lectura común, donde se une la literatura y la exploración práctica, porque «no son los lectores comunes, sino los teóricos, los que en ocasiones han sentido que la presión de una cuestión práctica, como una mano sudada sobre la exquisita cubierta de cuero, mancillaría la pureza de acabado del texto» (2005: 70).

En las secciones siguientes me ocuparé de esbozar una lectura de su «proyecto filosófico literario» que lo presenta basado en la experiencia literaria, y de rastrear en sus textos de los ochenta tanto el modelo conceptual de relación que plantea como las implicaciones en el ámbito de la filosofía moral al que se dirigía. Luego rastrearé los usos políticos en la esfera pública y el razonamiento jurídico que, apoyados en esos desarrollos iniciales, empiezan a vislumbrarse en los textos de la década de los noventa.

\section{EL DIÁLOGO ENTRE LA LITERATURA Y LA FILOSOFÍA MORAL}

En un trabajo publicado en 2009 NussBaum rememora los inicios y el trayecto de lo que llamó su «proyecto filosófico literario». Allí ubica el comienzo de la empresa en los primeros años de los ochenta, cuando presentó la primera versión de su trabajo «Cristales imperfectos» que luego sería publicado en un número especial de la revista New Literary History (NLH, 1983) y reeditado para su inclusión en CA [(1990) 2005], donde reunió la serie de ensayos de la década de los ochenta dedicados a reflexionar sobre las relaciones entre la literatura y la filosofía moral. NusSBAUM caratulaba allí 
su proyecto inicial como un «diálogo disciplinar», un espacio de conversación entre dos interlocutores diferentes que precisamente por esa razón tienen algo interesante para decirse. Lo alejaba entonces de otro tipo de proyectos que fundados en las similitudes, terminan desplegando lo que BALKIN llamó los lenguajes «coloniales» de la interdisciplina, aquellos que terminan en la asimilación o la subordinación del «otro» disciplinar (1996). En NuSSBAUM no es en primera instancia lo común lo que moviliza el encuentro entre ambos espacios — «las cualidades que hacen que las novelas sean tan diferentes de los tratados dogmáticos abstractos son, para nosotros, la fuente de su interés filosófico» (2005: 71)—, sino que como lo expresó también Jane ADAMSON, «lo fructífero de su relación depende de sus valores diferentes» (1998: 85) y lo que se busca es la posibilidad de generar lo que JOHNSON llamó «un terreno conversacional intermedio» entre dos interlocutores diferentes (2007: 24).

A pesar de las críticas a NuSSBAUM de reducir el valor de la literatura, instrumentalizarla al servicio de una moralidad simplista (POSNER, 1998), o producir lecturas que eliminan el «lenguaje especial de la literatura, arruinan la complejidad del significado, o buscan inmoderadamente la intención del autor»(COMPAGNON, 2005); en NussBaum es esa cualidad diferencial de la literatura lo que parecía necesitar la filosofía para repensarse a sí misma. En un trabajo posterior en donde reseña una serie de libros que vinculan lecturas de SHAKESPEARE con la filosofía (2008), sería más enfática en relación al descarte de proyectos de asimilación o subordinación de la literatura. Allí cuestiona el uso de textos literarios para identificar en ellos posiciones filosóficas familiares, transformándolos en un «manual básico para un curso introductorio a la filosofía» donde SHAKESPEARE aparece como «una especie de alumno que finalmente aprueba ese curso introductorio» y confirma las ideas que el filósofo «con cierto narcisismo» se complace en ver allí reafirmadas por la autoridad cultural (2008). Esa subordinación de la literatura al servicio de «ideas familiares» o de lo que «el filósofo ya pensaba» parece, a los ojos de NUSSBAUM, «no contribuir en nada a la filosofía o a SHAKESPEARE». En vez de considerar a la literatura como una pupila, como un objeto en el que confirmar ideas previas, NuSSBAUM propone tomarla como «guía» que abra el «asombro» del filósofo, un vehículo de pensamiento por derecho propio donde los aspectos estéticos o las cualidades literarias vinculadas a la forma y a la experiencia de lectura no solo deben tenerse en cuenta, sino que forman parte central de la contribución de la literatura a la filosofía moral (2008).

Ya en aquel ensayo publicado inicialmente en 1983, NuSSBAUM enfrentaba de lleno la pregunta sobre cuáles eran las características de las novelas que las volvían relevantes para el filósofo, por qué leerlas en el contexto de una indagación filosófica, y qué tipo de conocimiento indisponible por otros medios proporcionan (si es que lo hacen). Esta serie de preguntas, y el esbozo de respuesta que propone NussBaUM, fue lo que disparó la discusión y los comentarios de C. DiAmond, R. WOLlHeim, H. Putnam, i. a., en las páginas de NLH (1983, v. 15, n. 1), usualmente considerada como el hito fundacional de la discusión «ética y literatura» en el mundo angloamericano. Si bien este debate puede aparecer a primera vista como una marca del gusto exótico de un grupo de filósofos, y llevar entonces a circunscribir esa serie, en el mejor de los casos, como una subespecialidad — más o menos interesante o atractiva- encapsulada dentro de un panorama filosófico que permanece intacto; una lectura atenta de esta 
discusión inicial catapultada por NuSSBAUM permite ampliar el campo de miras. En la segunda parte de su trabajo, NuSSBAUM vincula la pregunta sobre el por qué de la inclusión de literatura a otra más amplia sobre qué es y qué debería ser la filosofía moral $^{6}$; es decir, la inclusión de literatura era entonces también parte de un proyecto de reforma de los modos en que esta se concebía en el panorama de la posguerra: incluía centralmente una reivindicación de la filosofía clásica y de la figura de Aristóteles frente a las tradiciones dominantes del kantismo y el utilitarismo; y presionaba por «la necesidad de una filosofía moral que reconozca modos de pensar e imaginar que no se focalicen exclusivamente en principios generales», que extienda su interés más allá del momento del juicio, que reconozca como parte de su lenguaje algo más que el argumento (NusSBAum, 2009). En sentido similar, ANTONACCIO señala que la discusión «ética y literatura», «es en el fondo una discusión sobre el carácter de la ética misma: si es mejor entenderla como una cuestión de obligación, centrada en la agencia autónoma y en principios universales, o si es una práctica de cultivo de visión moral y las virtudes requeridas para la percepción imaginativa de particulares en situaciones concretas» (2012: 75). HÄMÄLÄINEN destaca este mismo punto, y organiza los cambios que se plantearon durante los ochenta en la filosofía moral angloamericana a partir de la inclusión de literatura de maneras que pueden leerse con centro en este tramo inicial de la obra de NusSBAUM. Ella señala que la expansión del ámbito de la filosofía moral atravesó varios niveles e incluyó centralmente una serie de ítems que se conjugaron con discusiones que fueron concomitantes en el tiempo y en preocupaciones: particularismo/generalismo, teoría/antiteoría, y el revival de la ética de la virtud (2016). Esos niveles abarcaban «una insatisfacción con el foco exclusivo en los principios morales y la acción» y la presión por contemplar también dentro del radio de miras de la moralidad aspectos «vinculados al carácter y las virtudes, la percepción y las emociones». Por otro lado, el foco en la pregunta por el deber y la conducta interpersonal relegaba aspectos vinculados a preguntas más amplias que incluían el cómo debemos vivir aristotélico que NuSSBAUM reivindicaba como pregunta marco de su propia investigación. A estos dos niveles, agrega entonces el énfasis moderno «en enfoques procedimentales» que «se centran en lo correcto por sobre lo bueno» e hicieron posible una moralidad que funcionara independientemente de los compromisos que las personas tienen en el contexto de tradiciones e historias particulares (2016:39-40).

En ese contexto de replanteamiento del panorama filosófico de la posguerra, la propuesta de NuSSBAUM de inclusión de la literatura como un vehículo independiente de pensamiento ético tenía tres puntos u objetivos particulares ligados a las características diferenciales que encontraba en la literatura: i) el reconocimiento de la importancia ética de la contingencia; ii) el rol de las emociones y las pasiones en la vida ética, y iii) el lugar de la percepción y la particularidad en el juicio y la deliberación moral. Si bien NuSSBAUM ubica esos rasgos por momentos en los textos literarios mismos, en otras ocasiones que creo son mayoritarias y explican mejor su posición los ubica en la experiencia de lectura. Es en esa peculiar relación entre el lector y el texto en donde aparece de manera experiencial la contingencia, se agudiza la percepción y despunta también una dimensión afectiva. En este sentido, la diferencia de la literatura no gene-

${ }^{6}$ Allí precisa: «En primer lugar, para evitar confusiones, debemos tener una idea aproximada de qué es la filosofía moral y en qué consiste su tarea» (2005: 258). 
ra en NUSSBAUM una «teoría de la novela», de la literatura, o de la interpretación, sino que aparece como una relación y una experiencia particular con y a partir de un tipo de textos designados como literarios. Lo que llamó su «proyecto» de «diálogo entre filosofía y análisis literario», es una exploración de esa relación particular de los lectores con las obras literarias que ocurre en la lectura, y se sitúa «con respecto a esa actividad humana como lo haría una gramática descriptiva respecto al uso de la propia gramática por parte de un hablante nativo» (2005: 519).

Las formas de «uso» de la literatura que propone NussBAum y que desarrollaré en la sección que sigue centrados en la vulnerabilidad y la belleza, la percepción y la empatía, ofrecen todo un campo de exploración de los modos en que nos involucramos con las obras literarias cotidianamente. Gran parte del atractivo de NusSBAUM es esta apertura a explorar dimensiones de la experiencia de lectura descartadas por los marcos crítico-literarios profesionales que separan las emociones de la racionalidad, la crítica de la empatía, el ser afectado de la acción, la distancia de la involucración; que prefirieron el «agón» a la conexión sin más justificación. Esa apertura también abre la posibilidad de generar un puente entre el lector común que descansa en los orígenes de la posición crítica y la lectura profesionalizada, «una perspectiva menos despegada de experiencias ordinarias de lectura que preceden y sostienen a la crítica profesional: en vez de mirar a través de esas experiencias para ver las leyes ocultas que la determinan, las miramos de frente para investigar los misterios que están a simple vista» (FELSKI, 2015: 179) ${ }^{7}$.

\section{LOS USOS DE LA LITERATURA EN LA ESFERA PÚBLICA}

Durante la década de los noventa, NusSBAum gira sus intereses del ámbito amplio de la ética y el foco en la deliberación individual, hacia la filosofía política. Si bien desde su perspectiva ambos proyectos se solapan, pues la buena vida «en última instancia [se define] en relación a un "nosotros", es decir, a personas que desean vivir en comunidad y compartir una concepción del valor» $(2015: 43)^{8}$; hay un cambio de perspectiva hacia lo político y la esfera pública que puede presentarse como un «proyecto de sustracción» para acomodar su propuesta al marco del liberalismo político y el «consenso superpuesto» rawlsiano.

En este momento de su obra el derecho empieza a cobrar un protagonismo cada vez mayor; la función de la filosofía misma se reconsidera del amplio medio de «búsqueda de la sabiduría sobre nosotros mismos» (2005: 521) a presentar al filósofo como

7 VASTERLING (2007) y JOHNSON (2004) también se detienen en esta característica de NuSSBAUM de poner en el centro al «lector ordinario» como su gran marca. Los cito con cierta extensión: «Dejar espacio en la lectura filosófica de la novela al "lector ordinario" es importante. En Nussbaum este punto se convierte casi en su marca personal, una declaración de intención deliberada» (JOHNSON, 2004: 26). En la formulación posterior de Vasterling: «Nussbaum toma como punto de partida no al lector profesional sino al amateur [...]. Tomar al lector ordinario o amateur como punto de referencia no es una debilidad sino, por el contrario, uno de los puntos más fuertes del trabajo de Nussbaum» (2007: 83).

8 Así también lo especifica comentando a RiCOEUR y su proyecto aristotélico, «la persona que se pregunta por la buena vida, no desea una vida solitaria, sino una vida junto a otros. Más aún, para Ricoeur como para Aristóteles, el aspecto institucional de esta vida está incluido en el deseo del bien: el agente quiere vivir una vida buena completa con otros en instituciones justas» (2002a: 271). 
«abogado de la humanidad» (1995: 181); la literatura se corre del lugar central que había tenido durante los ochenta, y la pregunta ahora parece ser: «¿qué tanto de lo que he discutido en relación a la literatura dentro del pensamiento filosófico puede ser usado en la política y el derecho?»?

En este momento de usos políticos de la literatura de NussBaum se pueden ubicar centralmente JP (1995) y El cultivo de la bumanidad [CH (1998)] y de manera más indirecta y escueta Mujeres y desarrollo bumano [MDH (2000)], El ocultamiento de lo bumano [OH (2004)] y Fronteras de la justicia [FJ (2006)]. Inicialmente, puede pensarse este tramo en la obra de NussBAum en relación a la literatura, también como un momento de «sustracción». Donde antes Nussbaum leía densas y complejas novelas modernas que incluían al último Henry James, Dickens, Virginia WoOlF, BeCKETT; ahora, cuando el reclamo por el rol de la literatura se amplifica, se reduce correlativamente su corpus literario y aparece sobre todo la novela realista de «tema social» y junto a ella narraciones más finas y menos complejas de la experiencia de mujeres en India (en $\mathrm{MDH}$ ) y de padres con hijos discapacitados (en FJ y OH).

Lo que aparece aquí como un problema inicial es la introducción del vocabulario del «uso» de la literatura que implica, por un lado, sacar a la literatura «fuera de sí» hacia otros terrenos; y por otro lado, sacarla en una dirección —el «uso»— que se asocia a la instrumentalidad, la unilateralidad y el interés, cuestiones que usualmente quedan fuera de las consideraciones estéticas. Este es, por otra parte, el foco central de una de las polémicas que define con claridad los problemas del campo «derecho y literatura», la polémica entre NuSSBAUM y Richard POSNER. Y en la definición del «uso» o las posibilidades de expandir su significado más allá de la instrumentalidad directa y unilateral, se plantea también el carácter «dialógico» de la relación entre el derecho y la literatura que NussBaum había delineado en el ámbito de la filosofía moral y que se bosquejó en la primera sección de este trabajo.

En lo que sigue, intentaré una lectura de los «usos» de la literatura que propone NusSBAum incluyendo una reflexión sobre cómo esos «usos» extraliterarios pueden pensarse a la vez en términos estéticos clásicos, contra la acusación posneriana de perder en el camino la cualidad estética propia de la literatura. En este sentido, los usos que NusSBAum plantea están vinculados a la experiencia de lectura, pueden ser entendidos entonces como «usos» a la vez que exploraciones de «modos de involucración textual» (FELSKI, 2008), e incluyen una preocupación por la belleza (y la vulnerabilidad); la percepción (asociada a la mímesis literaria); y la imaginación empática (que NusSBAUM asocia al reconocimiento y a las emociones). Esos usos, a la vez, recuperan las tres cuestiones en las que NuSSBAUM localizaba la diferencia literaria en los textos de los ochenta en relación a los tratados filosóficos abstractos: i) un reconocimiento de la contingencia y su significancia ética; ii) el rol de la percepción y la particularidad en la deliberación moral, y iii) el valor de las emociones (2005).

9 En una entrevista publicada en 2011, NusSBAUM señala esta relación entre su trabajo en el terreno de la filosofía moral y la literatura por un lado, y en el del derecho, por otro. Allí explica que «su intervención principal ha sido pensar cómo las obras literarias brindan una perspectiva distintiva a la filosofía moral. Sobre eso trataba CA. ¿Qué implicaciones tiene eso para el derecho? [...]. Creo que mi trabajo empezó fuera del terreno del derecho. Era sobre filosofía y literatura. Pero tiene implicaciones para el derecho, porque el derecho lidia con cuestiones de justicia humana, como la filosofía, y entonces se enfrenta a las mismas cuestiones» (2011: 8). 


\section{LECTURA Y EXPERIENCIA DE VULNERABILIDAD}

El primer libro de Martha Nussbaum publicado luego de su tesis doctoral, Fragilidad (1986), comienza con un fragmento de una oda de PínDARO: «Pero la excelencia humana crece como una vid, nutrida del fresco rocío y alzada al húmedo cielo entre los hombres sabios y justos (Nemea, VIII, 40-2)». De ese fragmento NusSBAUM resalta una «sugerencia de la imagen poética, a saber, que la peculiar belleza de la excelencia humana reside justamente en su vulnerabilidad» y completa luego que esa excelencia humana «jamás podrá ser invulnerable y conservar al mismo tiempo su belleza distintiva» (cursiva añadida, 2015: 29-30). En FJ (2006), cuando su obra ya había desarrollado un doble énfasis en la vulnerabilidad y la autonomía, repetirá la misma imagen conectándola ahora con la dignidad humana: «[nuestra] dignidad, es la dignidad propia de un animal, una dignidad que no podría poseer ningún ser que no fuera mortal y vulnerable, del mismo modo que la belleza de un cerezo en flor no es la belleza de un diamante» (2007: 142). La vulnerabilidad, desde aquel libro de 1986, puede pensarse como uno de los hilos que conecta su obra a lo largo del tiempo ${ }^{10}$. Si bien es cierto, como señala HARPHAM, que luego de su experiencia en India la vulnerabilidad y la contingencia «no se ven tan bien en el contexto de pobreza» (2006), en 1993 ella misma aclara frente a los «malentendidos», que el pensamiento sobre la vulnerabilidad y la belleza de la vida humana en Fragilidad no implicaba que «la buena vida humana es buena (o hermosa) porque es frágil» y en consecuencia habría que maximizar toda forma de vulnerabilidad (1993: 56) ${ }^{11}$. También es cierto que, a pesar de su giro hacia KANT en los noventa en busca de un «sentido de la dignidad humana universal y, a fortiori, de la idea de la igualdad en valor y dignidad de los seres humanos» como lo destaca en el prólogo a la reedición en 2001 de Fragilidad, esa idea debe ser «corregida» por la insistencia en la vulnerabilidad humana aristotélica que sostenía en la edición original de 1986. Esta permite reconocer una continuidad entre la dignidad y la necesidad, la animalidad y la razón de los seres humanos que KANT (y los desprendimientos modernos de la doctrina estoica al separar el ámbito de la naturaleza y el reino moral de los fines) impiden ver, da sentido «urgente y esencial» a las obligaciones por el bienestar de los demás e incentiva la necesidad de una «distribución y redistribución correcta de recursos» (2015: xi); visibiliza la dignidad presente en la satisfacción de necesidades materiales, así como da un nuevo sentido a las relaciones «con los demás animales y con nuestra propia animalidad» (2015: xii). Toda su obra sobre las emociones que tiene su centro en Paisajes del pensamiento (2001), a su vez, puede verse como un desarrollo de la centralidad de esta idea de vulnerabilidad: las emociones tienen en común un elemento cognitivo mínimo de reconocimiento de la vulnerabilidad y asignación de valor a objetos externos fuera del control del agente.

10 Así lo sugiere Martha NuSSBAum en una entrevista fechada en 2011. Ante la pregunta sobre si «hay algún hilo conductor que atraviese esta diversidad de tópicos [que Nussbaum aborda]», la filósofa norteamericana contesta «[e]l tema común es la vulnerabilidad humana, o la vulnerabilidad en general» (2011a).

11 En el largo Prefacio a la reedición de Fragilidad en 2001, cuando sus preocupaciones se situaron de lleno en el pensamiento político, NuSSBAUM resalta este cambio «de acento»: «La importancia de no valorar la fragilidad como un fin en sí misma se pone claramente de manifiesto cuando se considera el pensamiento político», desde esa óptica, ciertas vulnerabilidades aparecen «como el resultado de sistemas políticos deficientes» (2015: xix). 
La vulnerabilidad como parte de la experiencia de humanidad no ha sido el foco de la filosofía y la teoría política asociadas al derecho, que se han centrado en la autonomía y la agencia invulnerable, autosuficiente e independiente como núcleo de la idea de persona política. En este punto, la relación parece invertirse en el mundo del arte literario. Como lo destaca Nussbaum, no solo el registro literario de la vida humana incluye prominentemente la vulnerabilidad, como lo sugiere el ejemplo de la planta en la oda de PíNDARO o como lo recuerda uno de los motivos de la expulsión de los poetas de la ciudad platónica: «Representan a héroes como Aquiles llorando y temiendo, y enseñan a los jóvenes a [...] identificarse con sus comportamientos no autosuficientes» $(2005: 686)^{12}$. La forma narrativa misma «conforma los deseos de los lectores, asignándoles una preferencia por el movimiento hacia adelante sobre el estancamiento, por el riesgo sobre la autosuficiencia» (2005: 651); y sobre todo, en la experiencia de lectura literaria experimentamos nuestra vulnerabilidad. Este último punto, la experiencia literaria como experiencia de vulnerabilidad, es el que NussBaum ha seguido primariamente para explorar el carácter diferencial de la literatura y el punto sobre el que articula sus diferencias con la prosa filosófica. Así, en CA (1990), establece la diferencia en los siguientes términos: «Leemos [la narración literaria] posponiendo el escepticismo, permitimos que nos conmueva el texto y los personajes que, con el tiempo, conversan con nosotros [...]. La actitud que tenemos ante un texto filosófico puede parecer, en contraste, conservadora e indiferente: pide razonar, cuestiona y escruta cada afirmación, desgaja la claridad de la oscuridad [...]. Ante una obra como esta nos sentimos humildes, abiertos, activos, y aun así llenos de poros. Ante una obra filosófica, durante su lectura, estamos activos, controladores, buscando no dejar flancos sin defensa ni misterio sin dilucidar [...]. No es solo emoción lo que falta, aunque ya es algo; también es pasividad, confianza, aceptación de la incompletitud» (2005: 506). Y es esta diferencia que enfatiza la vulnerabilidad, la que NussBAum parece querer aliar también a la actividad filosófica misma y no solo añadir a sus temas, para transformarla en una «filosofía a escala humana», que «haría mejor en ocuparse de un discurso mortal y de pensamientos mortales [...] que no se deje seducir por el señuelo del intelecto que se basta a sí mismo [...], que piense y hable más humanamente, reconociendo en el discurso la condición incompleta y necesitada de la vida humana, sus relaciones de dependencia y de amor con personas y cosas que escapan a nuestro control» (2005: 689).

La vulnerabilidad como contrapartida de la autonomía autosuficiente también aparece registrada en los personajes lectores de las novelas que lee NusSBAUM. En «Equilibrio perceptivo: teoría literaria y teoría ética», NuSSBAUM realiza una densa lectura de Los embajadores (1903) de Henry JAMES para avanzar un argumento sobre la moralidad de la percepción. Pero allí también aparece una lectura de uno de los personajes principales, el embajador Strether, que se distingue entre todos los habitantes

${ }^{12}$ De manera inversa, la autonomía ligada a la autosuficiencia e independencia es marginal en el registro literario. Así lo destaca NussBAUm en su respuesta al comentario de ELDRIDGE sobre CA: «Hay muy pocas novelas con un compromiso kantiano completo con la dignidad y la autosuficiencia de la voluntad moral -la forma misma lo resiste, construyendo un lector que, movido por el asombro, el suspenso y el amor por el sentido de que eventos azarosos en el mundo fuera y dentro del ser, tienen importancia» (1992: 202). Más adelante, en el mismo sentido señala que existe «una dificultad del filósofo de la autonomía [como SARTRE] para llegar a términos con el desordenado y accidentado mundo de la novela, lleno de encuentros, conflictos morales y amor» (1992: n. 12). 
de Woollett y su «mandamiento de "simplificar" en aras de la pureza y la seguridad» (2005: 338). Allí se pregunta: «¿Qué prepara a Strether para ver de este modo? ¿Por qué de todos los que salieron de América [...], solo él ha salido de verdad, abriéndose a las influencias de la percepción? Se nos ofrecen algunas pistas. Una, seguramente es su escaso sentido de su propia dignidad. Se encuentra tan lejos de afirmarla hasta el punto de permitir ser tratado, continuamente, como un agente de propósitos ajenos [...] su voluntad de servirla [a Mrs. Newsome] como embajador muestra un sentido kantiano de autonomía que no es lo bastante fuerte. Ronda la inquietante idea, en la que James insiste, de que su propia debilidad pueda ser la preparación necesaria para este otro tipo de fortaleza [...]. Pues desde el principio, Strether da muestras de sostener una relación profunda con la literatura [...], siente un amor profundo por el arte literario y, sobre todo, por la novela. La imaginación del lector y del escritor se presentan como las habilidades que lo han preparado para ver y responder de un modo no kantiano; [...] su amor juvenil por los relatos se agolpa en su memoria, avivando su deseo de esperar a las personas y acontecimientos novedosos con la mirada "generosamente dispuesta" del novelista, con una adorable y no sentenciosa atención a su particularidad» (2005: 335). En ese pasaje, el personaje lector también aparece asociado a una cierta vulnerabilidad que NuSSBAum liga a un valor y dignidad diferente a la dignidad kantiana, y esa vulnerabilidad parece ser la «preparación necesaria para otro tipo de fortaleza» que lo conecta con la multiplicidad de la vida y con los otros.

La experiencia de lectura literaria no solo permite leer sobre la vulnerabilidad humana — quizá la tragedia de su primer libro sea el lugar donde más ampliamente se registra este aspecto--, sino que cultiva también un sentido de la vulnerabilidad y de la aceptación de incompletitud y la corporalidad que está en la base de la sociabilidad humana y es la base de las relaciones igualitarias. Este quizá sea el principal punto de partida de $\mathrm{OH}$ (2004) para rechazar a las emociones del asco y la repugnancia en la vida democrática y el derecho. Allí se comienza explicando «que nuestra inseguridad es inseparable de nuestra sociabilidad y también de nuestra propensión a los vínculos emocionales; si nos vemos como dioses autosuficientes, no entenderemos los vínculos que nos unen a nuestros congéneres. Y esa falta de comprensión [...] engendra una perversión dañina de lo social, dado que las personas que se creen por encima de las vicisitudes de la vida tratan a los demás de modos que infligen, a través de la jerarquía, sufrimientos» (2006: 20). Y sobre el final del libro, se sostiene «que la imaginación y la fantasía, a menudo en relación con el arte y la literatura, son modos mediante los cuales los individuos pueden aprender a explorar los aspectos problemáticos de su humanidad sin angustiarse innecesariamente, y desarrollar así una noción más rica de sí mismos» que «aumenta la capacidad de imaginar las experiencias de los demás; ambas capacidades son cruciales, no solo para establecer relaciones personales satisfactorias, sino también para el funcionamiento de una sociedad liberal saludable» (2006:340). Esta reflexión se refuerza en Emociones políticas (2014), cuando NussBAum señala que una sociedad necesita un «espíritu poético, no solo unas reglas que promuevan esa igualdad de respeto, sino también por medio del juego y de la simpatía imaginativa, un ejercicio que incluya la vulnerabilidad y la disposición a renunciar a la omnipotencia, dos sentimientos propiciados por el espíritu "poético"» (2014: 231).

En $\mathrm{OH}$, la inclusión de la vulnerabilidad junto a la capacidad autónoma de las personas es quizá la modulación más importante que la literatura le imprime al liberalismo 
nussbaumniano (quizá también su característica más prominente) y sobre todo, a su imagen de la persona sujeto de derechos como un ser autosuficiente, independiente y completo. En este sentido pueden leerse los párrafos finales de la introducción que plantean que «el espíritu de este libro es menos afín a MiLl que a WHITMAN [...], propone una sociedad que reconozca su propia humanidad y que no nos oculte de ella, ni a ella de nosotros; una sociedad de ciudadanos que admitan que tienen necesidades y son vulnerables, y que descarten las grandiosas demandas de omnipotencia y completitud que han permanecido en el corazón de tanta miseria humana, tanto pública como privada [...]; lo que estoy proponiendo es una sociedad en la que tales ficciones autoengañosas no dominen el derecho y en la que —al menos en la creación de las instituciones que moldean nuestra vida en común - admitamos que somos niños y que en muchos sentidos no controlamos el mundo» (2006: 30).

La vulnerabilidad en el derecho incluye, según Martha FINNEMAN, «un sujeto más complejo alrededor del cual construir políticas sociales y derechos, que reemplaza al sujeto autónomo e independiente de la tradición liberal y es más representativo de la experiencia vital humana» (2008). Esas políticas basadas en la vulnerabilidad universal, según FINNEMAN, pueden sobreponerse a los problemas de las políticas de la identidad, que identifican grupos excluidos o postergados para controlar o revertir esa situación con el riesgo de estigmatizarlos y, por otro lado, no llegan a cubrir a todos los grupos minoritarios que coexisten en sociedades plurales. NuSSBAUM también registra, junto a otras reformulaciones feministas de la autonomía ${ }^{13}$, no solo las potencialidades políticas del registro de la vulnerabilidad de las personas que quedan oscurecidas por visiones de la autonomía tradicional, sino también los efectos dañinos de la imagen de persona que se basa en la autosuficiencia descorporizada, la independencia y el control: «El precio de la invulnerabilidad perfecta es demasiado alto» (2015: 408). Ese trabajo lo comienza en $\mathrm{OH}$ (2004) y lo expande en su reformulación de las teorías de la justicia contractualistas en FJ (2006). En OH, gran parte del argumento de oposición a otorgarle un rol político y una figuración en el derecho a las emociones de la vergüenza y la repugnancia está vinculado a cómo el mito del ciudadano autosuficiente y descorporalizado genera «vergüenza por la fragilidad humana, así como repugnancia ante los signos de nuestra animalidad» y cómo «ambas emociones están asociadas con formas de conducta social en las que un grupo dominante subordina y estigmatiza a otros grupos» proyectando en ellos su propia animalidad corporal y desvalimiento (2006: 381-382). De la misma forma, NEDELSKY señala que «las dimensiones corporales, afectivas e interdependientes del ser humano excluidas [del mito de la autosuficiencia descorporalizada] deben ir a algún lado, como de hecho han ido y se han adjudicado a las mujeres, las personas de color, y las clases trabajadoras» (2001: 249). Volver a colocar en el centro de la idea de dignidad tanto la capacidad racional de elegir y llevar adelante un plan de vida que presenta el derecho y la filosofía, como la corporalidad animal del ser humano y su fragilidad que registra la literatura (y pone en acto la experiencia de lectura) permite pensar de maneras más inclusivas tanto nuestra relación con los otros animales, como las políticas dedicadas a la vejez, la infancia, y el adecuado reconocimiento de las tareas de cuidado, así como también las formas de tratamiento de las discapacidades en la sociedad.

13 Entre las feministas de la autonomía relacional, quizá la figura más destacada sea la de Jennifer NEDELSKY $(2001,2011)$. 


\section{PERCEPCIÓN Y «FORMALISMO ALTIVO»: LA LECTURA Y EL RAZONAMIENTO JUDICIAL}

Aunque el foco para reconstruir las relaciones entre el derecho o el razonamiento jurídico y la literatura en NuSSBAUM ha sido comúnmente JP y primordialmente esas relaciones se centraron en la necesidad de incluir la empatía en aquel, quisiera centrarme aquí en otro trabajo de NUSSBAUM sobre la actividad de la Corte norteamericana durante 2006 (2007a). Cambiar el foco hacia ese trabajo creo que permite iluminar dos cuestiones. La primera es el marco general - un tipo de razonamiento particular que NusSBAum propone y vincula con la lectura literaria- en el que ese trabajo permite ubicar a la empatía, a la que me dedicaré en el siguiente apartado. La segunda razón es que este trabajo recupera una línea de continuidad entre los dos momentos en que puede dividirse la obra de NuSSBAUM — su etapa ética-aristotélica de la década de los ochenta y su etapa política-liberal posterior a 1990— y permite ver entonces el avance de un planteamiento sobre los usos de la literatura que no quiebra su obra en dos como usualmente sucede ${ }^{14}$. Ese trabajo, desde su subtítulo «percepción contra formalismo altivo», reintroduce en el vocabulario de la filosofía política de NuSSBAUM a la «percepción», que había sido el centro de su vocabulario moral y se vincula estrechamente con la idea de la vulnerabilidad tratada anteriormente.

Si bien podemos rápidamente asociar la percepción al mundo literario en distintos niveles que la incluyen como una facultad que despliega el autor, el artista, en su obra; como una destreza de los personajes para concebir las situaciones y a los demás, así como a cambiar su percepción a lo largo de una obra; o bien como algo que realiza el lector, una forma de atención que capturan los textos literarios y que ayudan a cultivar; también esta noción casi metafórica, débil, difusa y particularista, parece ajena al mundo del derecho y la deliberación práctica, su necesidad de categorías y de juicios certeros, su estructura adversarial, y la tendencia a la aplicación de normas y teorías o bien al razonamiento por subsunción. De hecho, como lo destaca HäMÄLÄINEN, la percepción no aparecía entre los términos de la filosofía moral del siglo XX, interesada en diferentes procedimientos para encontrar los principios correctos para la decisión moral que suele informar al pensamiento jurídico; pero adquirió un impulso y «una carrera destacada sobre el filo del milenio, y uno de sus espacios de desarrollo fue la discusión sobre ética y literatura» (2016: 25).

Las formas de atención aguda que involucra la percepción son parte para NussBaum, de la tarea de creación estética del novelista y correlativamente una de las dimensiones estéticas de la experiencia de lectura. Estas formas de atención, a su vez, también «nos ayudan a percibir los méritos del críptico dictum aristotélico "el juicio descansa en la percepción”» (NussBaum, 2000) que «deja demasiado a los juicios particularizados y uno no puede estudiar los méritos de esa concepción sin estudiar complejos casos de esos juicios particularizados» (Nussbaum, 1998). En este último

14 En la entrevista ya citada, NussBaum se pregunta: «Qué implicaciones tiene para el derecho [CA]? Bueno, esas mismas ideas sobre [...] la percepción aristotélica que conectaba con las novelas tienen implicancias para el derecho, se trata de una cualidad de la imaginación [...] que sería importante desarrollar en los jueces» (2011). 
sentido, las novelas - particularmente las de JAMES — muestran y ponen en acto en la lectura «cuán difícil es hacer justicia a todas las complejidades de una situación ética, y cuán indispensable es en esa situación la fina facultad de percepción» (2000).

NusSBAUM ubica la oscura expresión aristotélica que prioriza la percepción de los particulares «en relación con su ataque a otro rasgo de las representaciones seudocientíficas de la racionalidad: la insistencia en que la elección racional puede encerrarse en un sistema de reglas generales o principios que, de este modo, se pueden aplicar sencillamente a cada nuevo caso» (2005: 134). Este aspecto de la inclusión de la percepción de lo particular es lo que ha sido señalado como su mayor innovación en la filosofía moral y también su intento de reforma más exitoso. Así, LANDY señala que «NuSSBAUM está en lo correcto cuando dice que el comportamiento moral completo requiere no solo adherir a principios generales, sino también atención a los matices que tienden a escapar al ámbito de los principios» (LANDY, 2012: 38). Por su parte, HORTON también acuerda con que «las novelas proveen un complemento necesario al estilo de teorización moral que, bajo formas kantianas o utilitaristas, ha sido distorsionado por el foco estrecho y exclusivo en las reglas, principios generales e informados por concepciones de la racionalidad lánguidas» (1996: 76). Desde el punto de vista literario, Terry EAGLETON ha considerado que este cambio en la concepción de la moralidad se adecúa para pensar las «dimensiones morales de la literatura [...] al cambiar el significado de "moral" desde una cuestión de códigos y normas a una sobre significados humanos, valores y cualidades» (2012: 59). Estas dimensiones morales, en su recuento, forman parte de una familia de rasgos que ayudan precisamente a distinguir lo literario. De manera que aquí el argumento de NuSSBAUM no se refiere a la imposición de un código de lectura ajeno a las dimensiones literarias o artísticas de la literatura, sino a un rasgo y una habilidad que la lectura pone en marcha y cultiva, que es parte de la experiencia que tenemos de la literatura. La exploración de la percepción es la exploración de una de las dimensiones estéticas de la lectura. Y es esa dimensión de la lectura, la percepción y la atención, la que tiene un significado moral en el marco neoaristotélico que propone: «Hay una complicidad entre la conciencia del lector (y escritor) de relatos y la moralidad de la percepción. Pues los relatos cultivan nuestra habilidad para ver y prestar atención a los particulares, no tanto como representativos de una ley, sino como lo que suponen en sí mismos» (2005: 337).

El tipo de razonamiento en el que se basa NussBaum para desarrollar su concepción aparece por primera vez en los capítulos iniciales de Fragilidad, donde reflexiona sobre la lectura literaria. Allí, enfrentada a la lírica coral de Antígona, NussBAum señala: «Reflexionamos sobre un incidente, no ya subsumiéndolo en una regla general ni traduciendo sus rasgos a los elegantes términos del método científico, sino en primer lugar hundiéndonos en las profundidades de lo particular y alumbrando imágenes y conexiones que nos permiten contemplarlo más verdaderamente y describirlo con mayor riqueza; $y$, en segundo lugar, combinando dicha profundización con el hallazgo de conexiones horizontales, de modo que, por una parte, cada una de estas contribuye a la profundidad de nuestra visión de lo particular considerado y, por otra, cada profundización genera nuevas relaciones horizontales» (2015: 113-114).

La percepción, asociada también a la «visión» de MURDOCH o la «atención» de Simone WeIL, es la facultad de percibir o atender a los rasgos relevantes de una si- 
tuación. NuSSBAUM lo resume como un «entendimiento contextual y experiencial» (2007a: 25), y lista tres categorías de cosas que los principios generales, fijados de antemano a lo particular, no pueden capturar: los rasgos nuevos de las situaciones, el carácter contextual de los aspectos relevantes, y la relevancia ética de los seres particulares y las relaciones particulares (2005: 85-86). La inclusión de la «percepción» que en NuSSBAUM aparece como un adjunto de los principios a los que les impone ciertas características, tiende también a ampliar el foco de la deliberación moral de uno centrado en el momento de la elección (y la acción) a los momentos previos de descripción y redescripción de la situación; así como a modificar la escala, desde un razonamiento que comienza y sostiene una distancia alta de las situaciones particulares, hacia una escala más pequeña, que se mantiene cerca del contexto y la particularidad.

La prioridad de la percepción le imprime a la concepción del razonamiento de NussBAum no solo un aspecto de inmersión en los particulares y el contexto que se opone a la visión distanciada que suele asociarse al «punto de vista moral» y a las figuras judiciales de altas instancias que condensan los modelos de razonamiento jurídico; sino también una dosis de «improvisación» y flexibilidad que no aparece $-\mathrm{y}$ es lo que se tiende a evitar - en formas de razonamiento basadas en la subsunción de particulares en categorías prefijadas, en la aplicación de reglas generales (o principios), o «en la búsqueda de fijación y estabilidad [...] en el textualismo» (NuSSBAUM, 2007a: 26-27). Aquí NussBaum parece dejar a un lado, o situar en un nivel secundario, a la prolijidad teórica de los modelos de decisión, para poner en primer plano la respuesta a las situaciones concretas, la exploración de su complejidad, y la capacidad de revisión constante de marcos de percepción —en forma de reglas o principios - frente a lo particular situado.

En «Constitutions and Capabilities» (2007a) NuSSBAUM desarrolla estos rasgos del razonamiento perceptivo en el contexto judicial vinculado a su «enfoque de las capacidades». Allí opone el modelo de la percepción a lo que llama el «formalismo altivo». Este último es una visión que sostiene que el buen juicio requiere situarse a una considerable distancia de los hechos del caso y de la historia de lucha que frecuentemente revelan. No se trata solo de seguir reglas y principios, que si son «complejos y cercanos a la tierra», así como si se vinculan a la historia, serán parte del juicio perceptivo; sino de una «determinación a buscar y apegarse a cierto tipo de principios de alto grado de abstracción y distancia del contexto y la historia, sin importar que ese nivel de abstracción no sea el que mejor capture la complejidad del caso» (2007a: 28).

La percepción que NuSSBAUM señala como un ingrediente importante de las decisiones judiciales llama la atención sobre una cuestión subtratada en relación a la adjudicación judicial. Ella está vinculada a la importancia de la descripción y redescripción del caso en su contexto e historia particular: aquí la percepción indica que la tarea comienza mucho antes que el momento de la decisión, que la descripción correcta es un «logro moral» y que la actividad judicial puede asumir tonos más exploratorios o investigativos que adversariales y asertivos. Si bien NuSSBAUM está interesada en la lectura atenta de historias individuales de miembros de grupos desaventajados, de manera que los jueces analicen la historia de sus esfuerzos y localicen los obstáculos que enfrentan para gozar de los derechos, su atención en la percepción y en la exploración 
compleja de los problemas situados en contexto, puede ser particularmente atractiva para pensar modelos de actividad judicial en relación a casos estructurales —en particular aquellos que involucran derechos sociales y que no están desarrollados en el contexto norteamericano en el que NusSBAUM escribe- $-\mathrm{y}$ en este sentido puede sumarse a las nuevas miradas sobre la intervención judicial que se desarrollaron con esos casos en miras.

Si en relación a la vulnerabilidad la lección literaria al derecho era una lección de humildad, en cuanto a la percepción se trata de una de posibilidad, de imaginar posibilidades y no «ir hacia una situación con posibilidades fijas y dadas, donde los términos de elección, las alternativas, son algo por lo que uno no tiene responsabilidad» (DiAmOND, 1996). Cora DiAmOND lee el trabajo de Nussbaum sobre la percepción vinculado a la imaginación de posibilidades y a la improvisación. Contrapone allí la concepción del razonamiento moral de FrANKENA con la de NuSSBAUM: «Frankena va hacia una situación con posibilidades fijas y dadas [...]; el razonamiento moral consiste en aplicar principios y reglas en los hechos del caso. No se plantea la posibilidad de que el pensamiento moral tenga lugar en lo que toma como los hechos del caso, cómo se llega a verlos, cómo se los describe. Los hechos son los hechos, descríbelos y luego vendrá el trabajo moral: aplica tus principios [...]. El agente moral debe tomar las alternativas fijas y determinar cuál está apoyada por mejores razones». En NusSBAUM en cambio, «la improvisación señala una forma enteramente diferente de ver qué involucra la vida moral, la vida simpliciter, en la que la posibilidad y el ejercicio de la visión creativa están unidos» (1996). De igual manera que en el razonamiento moral, en la actividad judicial la descripción perceptiva del caso, y con ella la apertura de alternativas, también debería verse como parte del razonamiento jurídico que lo llevan más allá de tomar las «alternativas fijas y determinar cuál está apoyada por las mejores razones». La exploración de las complejas capas que involucran los problemas que llegan a los tribunales como una tarea que los jueces deben llevar a cabo y por la que son responsables es una cuestión que se ha puesto en el centro de escena judicial por los proponentes de «intervenciones dialógicas» $\mathrm{y}$ «experimentalistas» (GARGARELLA, 2014; SABEL y SimON, 2004), que también se apoyan en una concepción más flexible y con altas dosis de improvisación y «experimentación» judicial. De hecho, el paso de un «modo adversarial a uno investigativo» entre jueces y partes que se embarcan en «un esfuerzo por encontrar una nueva definición del problema y sus soluciones»; y donde se reconoce que «las obligaciones de reformar instituciones y responder a los derechos no están asignadas de antemano con precisión, sino que se van creando de forma conjunta durante el proceso» (GAURI y BRINKS, 2012: 425 426), se asemeja bastante a la idea de la prioridad de la percepción y la centralidad de la descripción compleja y no reductiva de los problemas, así como a la salida de esquemas de decisión donde las «posibilidades están fijadas de antemano» y solo resta elegir una u otra en un esquema de ganador y perdedor. La actividad del juez aquí se parece más a la del lector de Antígona, cuya actividad perceptiva reconstruía Nussbaum en Fragilidad como una en la que «no se reflexiona sobre un incidente [...] subsumiéndolo en una regla general ni traduciendo sus rasgos a los elegantes términos de un método científico», sino que se asemeja a la de «una araña en su tela, capaz de sentir y reaccionar al estirón que se produzca desde cualquier parte de su compleja estructura» (2015: 114). 


\section{LA IMAGINACIÓN EMPÁTICA: EL DERECHO Y LOS «OTROS»}

Si bien la empatía y la compasión no figuraban como preocupaciones centrales dentro de la obra de NuSSBAUM de la década de los ochenta, ambas son el foco de sus preocupaciones político-literarias luego de los noventa y llegaron a transformarse en la sinécdoque que resume todo su proyecto filosófico-literario. Este contraste es más claro si se toma como punto de comparación su primer libro. Allí, la empatía y la compasión tienen ocurrencias aisladas y solo son mencionadas sin exploración conceptual o de sus implicaciones para el argumento del libro ${ }^{15}$. Esta escasa presencia de lo que luego se transformará en el centro de su lexicón filosófico contrasta con la frecuencia con la que recurre allí al término «receptividad» que, en cambio y a diferencia de la empatía, aparece asociada no a la emoción compasiva, sino a otra emoción que luego no tendrá amplio desarrollo en su obra: el asombro ${ }^{16}$.

Sin embargo, a pesar de las diferencias intuitivas entre la empatía y la compasión por un lado, y la receptividad y el asombro por el otro, ambos grupos parecen vincularse en torno a las relaciones que establecemos con lo que parece distante, diferente, fuera de control inmediato por parte del agente en los términos de los filósofos morales o, en el vocabulario de los estudios literarios, está teñido de otredad. Esta relación con la otredad es lo que NuSSBAUM parece encontrar escenificado en la lectura literaria y es también lo que considera la «promesa política de la literatura»: «Que nos puede transportar, mientras seguimos siendo nosotros mismos, a la vida de otro, revelando similitudes, pero también las profundas diferencias entre él y yo, haciéndolas comprensibles o acercándose a ello»; o reformulado en relación a la vida cívica y en términos de «reconocimiento»: «La gran contribución de la literatura a la vida del ciudadano es su capacidad para arrancar de nuestras obtusas imaginaciones un reconocimiento de aquellos que no son como nosotros» (2005a: 147-148). La imaginación narrativa o empática que la literatura cultiva en sus lectores es, por otra parte, «un ingrediente esencial de una postura ética que nos insta a interesarnos en el bienestar de las personas cuyas vidas están distantes de las nuestras» porque «una ética de respeto imparcial por la dignidad humana no logrará comprometer a seres humanos reales a menos que estos

15 La empatía tiene una sola aparición en Fragilidad, en el capítulo 10 dedicado a la «Deliberación no científica» aristotélica, como una de las habilidades junto a la imaginación, la perceptividad y la flexibilidad del «hombre prudente» (2015: 395). La compasión, por su parte, solo se menciona al tratar la tragedia de Esquilo y el dilema de Agamenón (cap. 2) y en el epílogo centrado en la lectura de Hécuba de EuRípIDEs (2015: 503). En CA (1990), tanto la empatía, como fundamentalmente la simpatía y la compasión, ganan más terreno y preparan el camino que se seguirá en los noventa.

16 El asombro, por caso, no es trabajado en profundidad en el texto sobre las emociones por antonomasia (2001). Allí sin embargo, sí se lo caracteriza como una emoción anómala dentro del repertorio humano que sigue NuSSBAum por no ser eudaimonista: «La excepción más llamativa [a la estructura eudaimonista] parecería la emoción del asombro [...]. Esta emoción responde a la atracción que ejerce el objeto, y podría afirmarse que en ella el sujeto es máximamente consciente del valor del objeto, y solo es consciente en grado mínimo, o en ninguno, de la relación del mismo con sus propios planes» (2008: 76-77). Así como también se sugiere que el asombro «constituye en ocasiones un ingrediente de otras emociones» que matiza el elemento eudaimonista, o bien ayuda a «atraer objetos distantes hasta el ámbito del esquema de fines de una persona» (2008: 78). En este punto, podría pensarse al asombro en un punto intermedio entre las emociones (donde aparece por momentos en el esquema nussbaumniano) y los «estados mentales de la razón o el pensamiento». Agradezco este punto al revisor anónimo de la revista. 
sean capaces de participar imaginativamente en la vida de otros, y de tener emociones relacionadas con esa participación» (1997: 18).

Si bien se ha tendido a leer este argumento de manera lineal — la literatura cuenta historias sobre otros y genera o cultiva la empatía frente a extraños, esa empatía es uno de los pilares de la buena ciudadanía y del buen juez-, como un uso instrumental que saca a la literatura del ámbito estético para introducirla en una dudosa ética y política de la empatía; y por otro lado, como una confusión entre un ámbito de lectura privado y solitario que se proyecta sin más a otro público; también es posible leer el argumento - con sus problemas - de manera multidimensional, incluyendo dimensiones estéticas, políticas y éticas de la lectura que proyectan una forma de «uso» de la literatura más dialógico. Leído de esta forma, el argumento incluye un reclamo estético, que pide incluir dentro de la experiencia estética de lectura a lo que a veces llama empatía, otras reconocimiento, y en ocasiones imaginación participativa, narrativa o identificación empática. Por otro lado, parece establecer una relación entre ese aspecto de la experiencia de lectura que sucede en un ámbito privado y una determinada conducta moral (o un desarrollo moral, el cultivo de una habilidad moral imprescindible para la vida en común), cívica en el ámbito público, de atención y preocupación que se extiende más allá de los personajes y el mundo de ficción hacia las personas reales, una «política de la empatía» que llevaría a la acción pro-social e igualitaria. O bien, en un sentido diferente, establece una relación entre esa experiencia empática y una visión ética distinta de aquella basada exclusivamente en el «respeto imparcial» de la razón, para incluir un aspecto emocional. Estos tres aspectos permanecen entrelazados en la formulación nussbaumniana, de manera que es la estética de las obras literarias, a partir de sus propios recursos y sin perder su estatus como arte, la que interviene en la política y proporciona un punto de vista diferencial que se pone en diálogo con el «punto de vista moral» tradicional basado en una imparcialidad desapegada y distante. En otro espacio me dediqué a cada uno de estos aspectos o dimensiones de la empatía (SÁENZ, 2019), aquí me centraré en su dimensión «legal» y los problemas que aparecen cuando se la intenta incluir en el ámbito del derecho.

El capítulo final de JP se dedica a explorar el rol y las funciones de la imaginación empática y las «emociones humanizadoras» que involucra, en el ámbito de la práctica del derecho. Para ello se centra en la figura del juez — una figura en particular, el juez de altas instancias - y revisa una serie de casos constitucionales decididos por la Suprema Corte norteamericana y un tribunal de apelaciones federal que incluyen $\mathrm{Hudson}$ vs. Palmer (468 U.S. 517, 1984); Mary Carr vs. Allison Gas Turbine Division, General Motors Corp. (32 F. 3d 1007, 1994); Bowers vs. Hardwick (478 U.S. 186, 1986).

De la discusión que la autora genera en ese capítulo final quiero centrarme aquí en dos cuestiones que aparecen como el foco sobre el que giran otros desarrollos de la «empatía legal» y el tratamiento de la diferencia en el derecho. La primera es el problema de la imparcialidad y los modos de reformularla para acomodar allí a las emociones del entendimiento empático del otro diferente. La segunda está vinculada al modelo de juez y el espacio del juicio en el que la literatura de la empatía legal se centra, que es uno diferente del que aparecía entre los «hermenéuticos» del movimiento derecho y literatura que se ceñían a los jueces que interpretan documentos legales usualmente tomando como ideal a los jueces de altas instancias más cercanos al pensamiento abs- 
tracto y general de la teoría. Si bien NUSSBAUM parece tomar a las altas instancias también como modelo (y de allí toma sus ejemplos de «jueces literarios»), la inclusión del entendimiento empático parece también acercar esas altas instancias a zonas inferiores, más cercanas a lo particular de los casos, más proclives a lidiar con la confusa materia fáctica, y a lectores más amplios que se extienden desde los documentos legales a los complejos dramas humanos.

La otredad y la diferencia han desafiado a la idea de imparcialidad como abstracción de las emociones y la imaginación particularista, junto con su concepción de la razón sin cuerpo que desvincula a la facultad de juicio racional de los afectos (NEDELSKY, 2001) ${ }^{17}$. La empatía despierta los mismos recelos de parcialidad. Esto se volvió particularmente visible con la controversia que despertaron las declaraciones de 2009 del entonces presidente Barack Obama en relación a la nominación de jueces de la Corte Suprema donde expresó, entre otras cosas, que: «Voy a buscar a alguien que entienda que la justicia no se trata de una abstracta teoría legal o una nota al pie en un casebook. Se trata también sobre cómo nuestras leyes afectan las realidades diarias de las vidas de las personas [...]. Veo esa cualidad de empatía, entendimiento e identificación con las esperanzas y luchas de las personas, un ingrediente esencial para arribar a decisiones y resultados justos» ${ }^{18}$. La controversia, o «la guerra de la empatía» como la llamaron en la prensa, encendió críticas que la asimilaron al «prejuicio», la «parcialidad» o el «activismo» (WEST, 2011). En ese marco, la imaginación empática puede verse como antagonista del derecho, sea por un énfasis cultural en el «legalismo», un apego excesivo al formalismo y el seguimiento de reglas para dotar de autoridad y seguridad a las decisiones; debido a la cultura adversarial del derecho (HENDERSON, 1987); a «las reglas de los tribunales que requieren que uno no use un lenguaje considerado emocional, que hable en un paradigma legal basado en reglas de evidencia que destrozan las narrativas en pequeñas piezas» (DELGADO, 1996); o a una idea de neutralidad basada en la «altiva distancia respecto de los particulares» que se contrapone con la «llamada al contexto» del entendimiento empático (NussBaum, 1997: 118).

Según entiendo, la inclusión de la imaginación empática y las emociones que conlleva en la propuesta de NuSSBAUM no intenta desbancar el lugar del «razonamiento técnico legal, el conocimiento de la ley y los constreñimientos de los precedentes» que «desempañan una función central en el buen juicio, circunscribiendo los límites dentro de los cuales debe obrar la imaginación» (1997: 118). Pero sí implica una ampliación de la razón para incluir a las emociones como pensamientos evaluativos y modos de involucramiento con el valor humano de los hechos que presentan los casos. En este sentido, el «juez literario» empático e imparcial se opone a «un juez que cultiva el distanciamiento escéptico» o «concibe el razonamiento judicial según el modelo del razonamiento formal científico», «a un juez que prefiere una altiva distancia» de los «hechos concretos del caso y las historias de lucha que frecuentemente revelan» (NussBaum, 2007a: 26). Las narraciones, y la literatura, funcionan como señala Stephen BREYER

17 Jennifer NEDELSKY ofrece un recuento de tres posiciones con amplio impacto que vinculan la diferencia y las emociones para cuestionar el ideal de imparcialidad: la «ética del cuidado» de C. GILLIGAN, la teoría de la diferencia de I. M. YOung y el feminismo antiesencialista de E. SPELMAN (2001).

18 Declaraciones de 1 de mayo de 2009, disponibles en www.nytimes.com/2009/05/01/us/politics/01souter. text.html. 
en la audiencia de nominación para la Corte Suprema, como una manera de «bajar de la torre» y recordar que «cada una de las personas» que en la lejanía pueden parecer iguales, tiene una historia particular para contar. La empatía es, en su forma mínima, un reconocimiento de la humanidad situada en una historia contextual de las personas, y por otro lado, un recordatorio de la incompletitud del propio punto de vista, que no está ni podría estar en «la torre» de BREYER, sino que logra completarse desde abajo, imaginando empáticamente otras perspectivas.

La manera de incluir a las emociones en el juicio (o educar y evaluar las que ya están allí) y sostener a la vez el ideal de imparcialidad de NusSBAUM, se basa en un «dispositivo de filtración» que toma de Adam SMITH y de lo que considera es la posición del lector de literatura: el espectador juicioso. Esa figura artificial ayuda a distinguir cuáles serán las emociones apropiadas del buen juez. El espectador juicioso es, primero que nada, un espectador no implicado en la situación, pero que la observa de cerca «como un amigo preocupado» (1997: 108). Es distante en el sentido de no implicado personalmente, pero mira de cerca la situación con todos sus detalles y su densidad contextual, y su posición es rica en emociones. El espectador «no tendrá las emociones y los pensamientos concernientes a su seguridad personal; y en ese sentido será imparcial» (1997: 108), pero en él «no se distingue la razón de la emoción» porque una de sus «facultades morales más importantes es la capacidad de imaginar claramente en qué consiste ser cada una de las personas cuya situación él se imagina» (NussBAum, 1997: 108). Así, en los ejemplos de Nussbaum, el juez Stevens en Hudson vs. Palmer reconstruye el punto de vista del prisionero para calibrar el daño que genera la inspección violenta de su celda y determinar el alcance del derecho a la privacidad desde ese punto de vista; y POSNER puede señalar que existió acoso hacia Mary Carr reconstruyendo, desde el punto de vista de esa mujer en esas circunstancias, el significado de lo que el supervisor de la fábrica no «consideraría ofensiv[o]». En estos casos, las emociones funcionaron como recordatorios de la incompletitud del propio punto de vista del juzgador e impulsaron a reconstruir vívidamente las perspectivas del prisionero en «Hudson» y de la mujer en «Mary Carr». En esos casos, los jueces de altas instancias se involucraron con una reconstrucción densa de los hechos que incluían las perspectivas y el significado humano para sus propios protagonistas, y que usualmente asociamos a la actividad menor que llevan a cabo los jueces inferiores. Como señala SCHEPPELE, la distancia en relación a los hechos aumenta de manera correlativa al ascenso en la estructura judicial, de manera que los jueces de las instancias bajas lidian ante todo con la materia confusa de las situaciones fácticas y responden de manera directa ante las partes, y las instancias superiores van especializándose en el encuadre jurídico técnico. Lo mismo ocurre, en general, con los sistemas de jurados y la división del trabajo y los saberes: los legos son los encargados de los hechos; los jueces letrados, del derecho (SCHEPPELE, 1990). La regla implícita en este esquema parece indicar que, a mayor autoridad, mayor distancia de los hechos, de la cara humana de los casos, de la compleja historia de luchas detrás de cada derecho. Y, correlativamente, la autoridad y la imparcialidad aumentan cuando aumenta la distancia.

De hecho, la empatía está asociada a espacios de juicio cercanos a los hechos y las personas, «a bajas instancias legales, encuentros de abogados y clientes o jueces que enfrentan los hechos en primera instancia», y los proponentes de la empatía y las narraciones se han centrado «no en las cortes de apelaciones, sino en juicios orales 
que ponen a circular historias concretas»y en los encuentros entre jueces, partes y abogados (HENDERSON, 1987). Aún en ese marco dominante que confina la empatía a las instancias inferiores, tanto HENDERSON como NUSSBAUM proponen incorporarla a los procesos que transcurren en las altas instancias. Para ello, NuSSBAUM enfatiza la necesidad de pensar en un modelo de juez capaz no solo de leer documentos técnicos legales y «decir el derecho», sino de leer los hechos y su significado humano y social, así como de reconocer la incompletitud de su perspectiva y la necesidad de reconstruir la de los otros. Lynne HENDERSON, por su parte, basa su análisis en las audiencias orales que ocurren ante la Corte norteamericana como espacios de encuentro entre jueces, abogados y partes. En ambas, el argumento por la inclusión de la empatía como ingrediente del razonamiento legal es también uno que modifica la imagen de los jueces de altas instancias usualmente asociados a la lectura de documentos técnicos alejados del examen fáctico y contextual de los problemas, los pone en un mayor contacto con las perspectivas de los participantes en los casos y los sumerge en la exploración de las complejidades contextuales de los problemas que involucran. En este punto, si bien el planteamiento de NussBAum sobre la imaginación empática de los jueces ha sido asociado a una forma «monológica» de actuación judicial en donde la reconstrucción de la perspectiva de otros en la imaginación de los jueces suple la necesidad de escucharlos; también se podría pensar que el ideal del juez empático que propone puede incluir una dimensión de reestructuración del espacio de juicio, de manera que incluya esas otras perspectivas por sí mismas y en la propia voz de las personas involucradas en los casos. En otro espacio hemos argumentado, junto a Miguel BENEDETTI, que la inclusión de audiencias públicas que involucren la participación de abogados y partes de los juicios en el repertorio de prácticas institucionales de la Corte argentina tiene la potencialidad de generar espacios de juicio más empáticos, contextuales, sumergidos en la complejidad fáctica y que disminuyan el tono adversarial hacia uno más conversacional (BENEDETTI y SÁENZ, 2016: 169-170). En este sentido, las propuestas por la consideración de la empatía como un ingrediente del razonamiento judicial y una habilidad judicial valiosa pueden extenderse hacia un rediseño institucional que contemple un rol judicial más alejado de la torre que señalaba BREYER, y más cercano a la sociedad y las experiencias de las personas a las que se dirige.

\section{CONCLUSIONES}

En este trabajo presenté una lectura de la obra de Martha NussBaum que espero permita vislumbrar cuál es su aporte distintivo a la discusión sobre las relaciones entre el derecho y la literatura. Para ello, amplié el corpus que suele tomarse como base y que usualmente se limita a JP (1995), para incluir su trabajo previo y posterior en el área que, en el marco de una periodización de su obra que destaque los cambios y reorientaciones, creo que ilumina —además de ciertas continuidades en su obrauna respuesta o una serie de orientaciones sobre cuál es el valor de la literatura para el derecho, los usos que allí pueden dársele, y los efectos de esa alianza. Recuperar su proyecto presenta dos atractivos adicionales: por un lado, porque abre el panorama del «movimiento derecho y literatura» asociado muchas veces de manera excluyente a las firmas de la Alta Teoría con auge durante las décadas de los setenta e inicios de 
los ochenta hacia un rumbo diferente, señalando que la afinidad del derecho puede no estar vinculada a plataformas teóricas de amplia escala, sino precisamente a lo contrario, a introducir a las obras literarias mismas para señalar los límites de esos modelos abstractos; por otro lado, presenta un mapa de exploración de la experiencia de lectura ordinaria o común que los críticos literarios profesionales habían dejado de lado y que merece, al menos, ser discutido.

\section{BIBLIOGRAFÍA}

AdAmson, J., 1998: «Against tidiness», en J. AdAmson, R. Freadman y D. PArKer (eds.), Renegotiating Ethics in Literature, Philosophy, and Theory, New York: Cambridge University Press, 84-112.

Antonaccio, M., 2012: A Philosophy to Live By, Oxford: Oxford University Press.

BALKIN, J., 1996: «Interdisciplinarity as colonization», 53 Washington E Lee Law Review, 949.

BARON, J., 1999: «Law, Literature and the Problems of Interdisciplinarity», Yale Law Journal, 108, 1059-1085.

Benedetti, M., y SÁenz, M. J., 2016: Las audiencias públicas de la Corte Suprema. Aperturas y limites de la participación ciudadana, Buenos Aires: Siglo XXI.

Botero Bernal, A., 2014: «¿La lectura literaria forma buenos jueces? Análisis crítico de la obra "Justicia Poética"», Revista In Jure, año 3, núm. 5, 34-91.

Compagnon, A., 2005: «What is Literature for?», lección inaugural en el College de France, disponible en bttp://books.openedition.org/cdf/3314?lang=es.

Delgado, R., 1996: «Rodrigo's Eleventh Chronicle: Empathy and False Empathy», 84 Cal. L. Rev., 61.

Diamond, C., 1996: «Missing the Adventure: Reply to Martha Nussbaum», The Realistic Spirit, Cambridge: The MIT Press, 309-318.

Eagleton, T., 2012: The Event of Literature, New Haven: Yale University Press.

FELSKI, R., 2008: The Uses of Literature, Malden, MA/Oxford: Blackwell.

- 2015: The Limits of Critique, Chicago: University of Chicago Press.

Finneman, M., 2008: «The Vulnerable Subject: Anchoring Equality in the Human Condition», Yale Journal of Law and Feminism, vol. 20 (1), 1-23.

Gargarella, R. (comp.), 2014: Por una justicia dialógica. El poder judicial como promotor de la deliberación democrática, Buenos Aires: Siglo XXI.

GAURI, V., y BRINKS, D., 2012: «Human Rights as Demands for Communicative Action», Journal of Political Philosophy, 20 (4), 407-431.

HÄMÄLÄINEN, N., 2016: Literature and Moral Theory, New York: Bloomsbury.

HARPHAM, G., 2006: The character of criticism, New York: Routledge.

Henderson, L., 1987: «Legality and Empathy», Michigan Law Review, vol. 85, 1574-1653.

Horton, J., y Baumeister, A. (eds.), 1996: Literature and the Political Imagination, London: Routledge.

Johnson, P., 2007: Moral philosophers and the novel: a study of Winch, Nussbaum and Rorty, New York: Palgrave Macmillan.

Landy, J., 2012: How to do Things with Fiction, Oxford: Oxford University Press.

NeDELSKY, J., 2001: «Embodied diversity and the challenges to law», en R. BEINER y J. NEDELSKY (eds.), Judgment, Imagination, and Politics: Themes from Kant and Arendt, Boston: Rawman \& Littlefield, 229-256. 
- 2011: Law's Relations. A Relational Theory of Self, Autonomy, and Law, New York: Oxford University Press.

Nussbaum, M., 1986 (2015): La fragilidad del bien. Fortuna y ética en la tragedia y la filosofía griega, Madrid: La balsa de la medusa.

- 1990 (2005): El conocimiento del amor. Ensayos sobre filosofía y literatura, Madrid: A. Machado.

- 1991: «The Literary Imagination in Public Life», New Literary History, 22 (4), 877-910.

- 1992: «Reply to Richard Eldridge», Arion: A Journal of Humanities and the Classics Third Series, vol. 2, núm. 1 (Winter), 198-207.

- 1993: «Reply to papers», Philosophical Investigations, 16:1, 46-86.

- 1999: Sex and Social Justice, Oxford: Oxford University Press.

- 1995: «Lawyer for humanity": Theory and Practice in Ancient Political Thought», Nomos, vol. 37, 181-215.

- 1995 (1997): Justicia Poética, Chile: Andrés Bello.

- 1997: «Capabilities and Human Rights», Fordham Law Review, 66, 273-300.

- 1998: «Exactly and Responsible: A Defense of Ethical Criticism», Philosophy and Literature, $22,364-386$.

- 1998 (2005a): El cultivo de la humanidad. Una defensa clásica de la reforma en la educación liberal, Barcelona: Paidós.

- 2000: «Aristotle, Politics, and Human Capabilities: A Response to Antony, Arneson, Charsworth, and Mulgan», Ethics, vol. 111, núm. 1 (oct.), 102-140.

- 2000 (2002): Las mujeres y el desarrollo bumano, Barcelona: Herder.

- 2001 (2008): Paisajes del pensamiento. La inteligencia de las emociones, Barcelona: Paidós.

- 2002: «Ricoeur on Tragedy. Teleology, Deontology, and Phronesis», en J. Wall, W. SChweIKer y D. Hall (eds.), Paul Ricoeur and Contemporary Moral Thought, New York: Routledge.

- 2004 (2006): El ocultamiento de lo bumano: repugnancia, vergüenza y ley, Buenos Aires: Katz.

- 2006 (2007): Las fronteras de la justicia, Barcelona: Paidós.

— 2007: «Constitutions and Capabilities: "Perception” Against Lofty Formalism», Harvard Law Review, 121, 4-97.

— 2008: «Stages of Thought», The New Republic, 7 de mayo.

- 2009: «Ralph Cohen and the Dialogue between Philosophy and Literature», New Literary History, vol. 40, núm. 4, Tribute to Ralph Cohen (Autumn ), 757-765.

- 2011a: «Interview with Martha C. Nussbaum», disponible en https://www.lawandliterature.org/area/documenti/Interview\%20with\%20M.C. \%20Nussbaum\%20by\%20M.\%20 Cuccu.pdf.

— 2011b: «Entrevista a M. Nussbaum», disponible en bttp://ar.globedia.com/entrevista-martha-nussbaum-fina-birules-anabella-tullio.

- 2014: Emociones políticas, Barcelona: Paidós.

Peters, J. S., 2005: «Law, Literature, and the Vanishing Real: On the Future of an Interdisciplinary Illusion», PMLA, 20, núm. 2, 442-452.

Phelan, J., 2007: Experiencing Fiction, Ohio: The Ohio State University Press.

Posner, R., 1998: Law and Literature, Cambridge: Harvard University Press.

SABEL, C., y SimON, W., 2004: «Destabilization Rights: How Public Law Litigation Succeeds», 117 Harv. L. Rev., 1015.

SÁENZ, M. J., 2014: «Literatura y derechos humanos: un “campo naciente” », Revista Derecho y Ciencias Sociales, núm. 10, 24-55. 
— 2019: «Reconsiderando la empatía en el movimiento “derecho y literatura”», Revista Derecho del Estado, núm. 42, en prensa.

SCHEPPELE, K. L., 1990: «Facing Facts in Legal Interpretation», en R. POST (ed.) Law and the Order of Culture, Berkeley: University of California Press, 42-77.

STOW, S., 2007: Republic of readers? The literary turn in political thought and analysis, Albany: State University of New York Press.

Vastering, V., 2007: «Cognitive Theory and Phenomenology in Arendt's and Nussbaum's Work on Narrative», Human Studies, vol. 30, núm. 2, 79-95.

VLASCOS, S., 2014: Ricoeur, Literature and Imagination, UK: Bloomsbury.

Vogler, C., 2007: «The Moral of the Story», Critical Inquiry, vol. 34, núm. 1, 5-35.

West, R., 2011: «The Anti-Empathic Turn», Georgetown Law Faculty Publications, 678, disponible en bttp://scholarship.law.georgetown.edu/facpub/678.

- (ed.), 2015: Nussbaum and the Law, UK: Routledge. 
